\title{
Strategi Komunikasi Pencegahan Korupsi Melalui Film Pendek (Studi Kasus Kampanye Anti-Corruption Film Festival ACFFEST 2018)
}

\author{
Sandy Permata, Lufti Avianto \\ Universitas Mercu Buana, Komisi Pemberantasan Korupsi
}

\begin{abstract}
Abstrak
Film merupakan salah satu medium yang digunakan KPK dalam melakukan pendidikan dan kampanye antikorupsi, khususnya bagi generasi muda. Untuk itu, KPK menyelenggarakan program Anti-Corruption Film Festival (ACFFest) pada 2018. Dari film bermuatan nilai antikorupsi diyakini akan efektif memberikan pengetahuan, meningkatkan kesadaran yang pada akhirnya mengubah perilaku masyarakat. Dalam program ini, KPK memilih tujuh proposal yang kemudian diproduksi menjadi film dengan program pendampingan yang komprehensif untuk memastikan kualitas secara teknis perfilman dan substansi nilai antikorupsi yang tepat. Tujuan dari penelitian ini untuk mengetahui strategi komunikasi yang dilakukan KPK dalam program ACFFest 2018. Serangkaian strategi komunikasi, baik berupa promosi kegiatan, maupun melalui media massa cetak dan online, serta media publikasi online dan media sosial yang dikelola KPK. Penelitian ini menggunakan metode penelitian kualitatif, dengan pendekatan studi kasus. Hasil penelitian ini menunjukkan bahwa KPK telah berhasil menyelenggarakan program ACFFest 2018 dengan indikator output jumlah proposal yang dihasilkan melebihi target yang ditetapkan. Selain itu, melalui format kompetisi proposal, KPK juga memiliki ruang yang lebih luas untuk mengontrol terhadap kualitas teknis film dan substansi pesan pada tujuh film yang dihasilkan.
\end{abstract}

Kata kunci: Strategi Komunikasi, Kampanye Antikorupsi, Film Pendek

\begin{abstract}
Movie is one of the mediums used by the KPK in conducting anticorruption education and campaigns, especially for the younger generation. To that end, the KPK organized the Anti-Corruption Film Festival (ACFFest) program in 2018. Movies with anti-corruption values are believed to be effective in providing knowledge, increase awareness which ultimately changes people's behavior. In this program, the KPK selected seven proposals which were then produced into short movie with a comprehensive mentoring program to ensure the technical quality of the movie and the appropriate anti-corruption value substance. The purpose of this study was to find out the communication strategies carried out by the
\end{abstract}


KPK in the ACFFest 2018 program. A series of communication strategies, both in the form of promotional activities and through print and online mass media, as well as online publication media and social media managed by the $K P K$. This study uses qualitative research methods, with a case study approach. The results of this study indicate that the KPK has successfully held the ACFFest 2018 program with the output indicating the number of proposals produced exceeded the target set. In addition, through the proposal competition format, the KPK can also control the quality of the film, both technically and the message substance in the seven films produced.

Keywords: Communication Strategy, Anti-corruption Campaign, Short Movie

\section{Pendahuluan}

Dari 20.363 berita di media cetak dan televisi yang dipantau, sebanyak 58,55 persen merupakan berita di bidang penindakan, sedangkan berita di bidang pencegahan hanya sebesar 12,64 persen, diikuti berita tentang kelembagaan sebanyak 28,81 persen.

Berita di bidang penindakan, meliputi kegiatan Operasi Tangkap Tangan (OTT), penetapan tersangka, perkembangan kasus yang ditangani, persidangan kasus korupsi, kegiatan penggeledahan, penyitaan, perampasan hingga pelelangan barang rampasan hasil tindak pidana korupsi. Sementara berita di bidang kelembagaan berkenaan dengan KPK secara organisasi, seperti rekrutmen sekretaris jenderal KPK, teror terhadap penyidik dan pimpinan KPK, kebijakan rotasi dan mutasi, dan pelemahan KPK. Berita di bidang pencegahan meliputi kegiatan yang berkaitan dengan laporan harta kekayaan penyelenggara negara (LHKPN), pengendalian dan pelaporan gratifikasi, serta kegiatan pendidikan dan kampanye program antikorupsi.

Pemantauan tersebut, dilakukan terhadap 30 media massa, dengan rincian 13 surat kabar nasional, 13 surat kabar lokal/daerah, empat majalah berita nasional dan dua televisi berita.

Tabel 1.

Perbandingan Pemberitaan KPK Tahun 2018.

\begin{tabular}{llll}
\hline No & Kategori & Jumlah & Persentase \\
\hline 1 & Penindakan & 11.923 & $58.55 \%$ \\
2 & Pencegahan & 2574 & $12.64 \%$ \\
3 & Kelembagaan & 5866 & $28.81 \%$ \\
\hline & Total & 20.363 & $100 \%$ \\
\hline
\end{tabular}

Sumber: Biro Humas KPK. 
Salah satu upaya kreatif di bidang pencegahan korupsi itu dilakukan dengan pendekatan penyelenggaraan Festival Film Antikorupsi atau AntiCorruption Film Festival (ACFFest) 2018 dengan tema "Integrity Start From You, Make Your Movie", merupakan yang ke-4 kalinya sejak diselenggarakan pertama pada 2013. Survei yang dilakukan Saiful Mujani Research \& Consulting (SMRC) tentang Memahami Pola Menonton Kelas Menengah Urban Muda Jakarta di tiga universitas pada 2015: 60,6 persen sangat suka menonton film, cukup suka 36,4 persen. Artinya, ada 97 persen yang berpotensi menonton film sebagai bentuk hiburan kaum muda. Menyuntikkan nilai-nilai antikorupsi ke dalam sebuah film merupakan hal strategis yang dapat dilakukan dalam upaya pencegahan korupsi.

\section{Kajian Literatur}

\section{Strategi Komunikasi dan Model Perencanaan Komunikasi KAP}

Menurut Rogers dalam Hafidz Cangara (2013: 74): strategi komunikasi sebagai suatu rancangan yang dibuat untuk mengubah tingkah laku manusia dalam skala yang lebih besar melalui transfer ide-ide baru (Cangara, 2013:61). Sedangkan Middleton mengemukakan, kombinasi yang terbaik dari semua elemen komunikasi mulai dari komunikator, pesan, saluran, penerima sampai pada pengaruh (efek) yang dirancang untuk mencapai tujuan komunikasi yang optimal (Cangara, 2013:6.

Pelaksanaan acara Anti Corruption Film Festival (ACFFest) 2018 tersebut merupakan sebuah upaya KPK melakukan tindakan pencegahan (preventif) tindak korupsi yang dapat saja melingkupi semua sektor dalam kehidupan masyarakat. Maka dibutuhkan sebuah perencanaan komunikasi yang berbasis Knowledge, Attitude, Practice (KAP). Model perencanaan komunikasi berbasis KAP, bisa diaplikasikan untuk program-program berbagai bidang, khususnya untuk program penyadaran masyarakat.

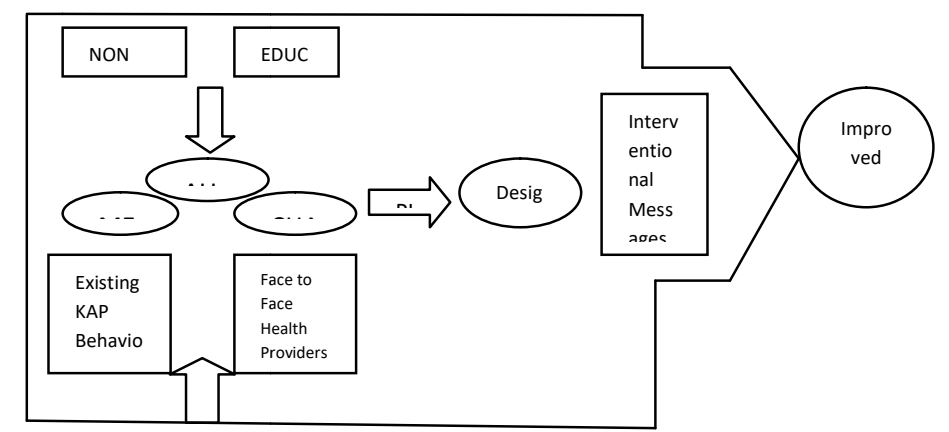

Gambar 1. Model perencanaan komunikasi berbasis Knowledge, Attitude, dan Practice (KAP) 
Dalam model ini ada tiga tahapan yang harus dilalui untuk melakukan program komunikasi, yaitu:

Tahap 1 : Mencakup target sasaran (audience), pesan dan saluran.

Tahap 2 : Mencakup perencanaan untuk melakukan desain pesan, produksi media (draft), dan uji coba (pre-testing).

Tahap 3 : Peningkatan pengetahuan (knowledge), sikap (attitude) dan perilaku (practice) target sasaran yang diharapkan.

Menurut Hafied Cangara (2013:87), pada tahap pertama, perencana komunikasi harus memperhitungkan faktor-faktor yang bisa mempengaruhi khalayak (audience) dalam penerimaan informasi. Faktor tersebut bisa berasal dari luar pendidikan (non education) dan juga dari masalah pendidikan (education problems). Faktor yang bersumber dari luar pendidikan antara lain: Budaya dan nilai, geografis, pendapatan, lingkungan, ideologi, dan kepercayaan. Sedangkan faktor lainnya adalah masalah masalah yang berkaitan dengan pendidikan.

\section{Film sebagai Media Efektif Penyebar Pesan}

Menurut Biagi (2010), film menjadi cermin masyarakat yang menciptakan mereka. Beberapa pembuatan dasar film menawarkan pesan politik. Film lain mencerminkan nilai-nilai sosial, meski beberapa film-film lainnya hanya baik untuk hiburan.

Sebagai salah satu dari bentuk komunikasi massa, karakteristik dari sebuah komunikasi massa. Antara lain:

1. Komunikator Terlembagakan., komunikator dalam komunikasi massa itu bukan satu orang, tetapi kumpulan orang-orang. Artinya, gabungan antar berbagai macam unsur dan bekerja satu sama lain dalam sebuah lembaga.

2. Pesan Bersifat Umum, Pesan-pesan dalam komunikasi massa tidak ditujukan kepada satu orang atau satu kelompok masyarakat tertentu. Oleh karenanya, pesan komunikasi massa bersifat umum.

3. Komunikatornya Anonim dan Heterogen, komunikator tidak mengenal komunikan (anonim), karena komunikasinya menggunakan media dan tidak tatap muka. Disamping anonim, komunikan komunikasi massa adalah heterogen, karena terdiri dari berbagai lapisan masyarakat yang berbeda.

4. Media Massa Menimbulkan Keserempakan, komunikasi massa itu ada keserempakan dalam proses penyebaran pesan-pesannya. Serempak disini berarti khalayak bisa menikmati media massa tersebut hampir bersamaan.

5. Komunikasi Mengutamakan Isi Ketimbang Hubungan, dalam komunikasi massa, pesan harus disusun sedemikian rupa berdasarkan sistem tertentu dan disesuaikan dengan karakteristik media massa yang akan digunakan.

6. Komunikasi Massa Bersifat Satu Arah, komunikator dan komunikannya tidak dapat melakukan kontak langsung. Komunikator aktif menyampaikan pesan, komunikan pun aktif menerima pesan, namun diantara keduanya tidak dapat melakukan dialog.

7. Stimulus Alat Indra "Terbatas", dalam komunikasi massa, stimulus alat indra bergantung pada jenis media massa. Pada surat kabar dan majalah, pembaca hanya 
melihat. Pada radio siaran, khalayak hanya mendengar. Sedangkan pada media televisi dan film, menggunakan indera penglihatan dan pendengaran.

8. Umpan Balik Tertunda (Delayed), efektivitas komunikasi seringkali dapat dilihat dari feedback yang disampaikan oleh komunikan.

Film sebagai media kampanye antikorupsi dijadikan alat penyebaran informasi persuasif agar masyarakat paham bahwa tindak korupsi dapat dicegah sedini mungkin, dimulai dari diri kita sendiri. Menurut pasal 1 ayat (1) Undang-Undang Republik Indonesia nomor 33 Tahun 2009 Tentang Perfilman (UU baru tentang Perfilman), "Film adalah karya seni budaya yang merupakan pranata sosial dan media komunikasi massa yang dibuat berdasarkan kaidah sinematografi dengan atau tanpa suara dan dapat dipertunjukkan.

\section{Film Pendek sebagai Media Kampanye Budaya Antikorupsi}

Film pendek yaitu sebuah karya film cerita fiksi yang berdurasi kurang dari 60 menit, dan di berbagai negara, film pendek dijadikan tempat bereksperimen dan jalan masuk bagi para pembuat film untuk memproduksi film panjang. (Panca Javadalasta, 2011).

Film pendek adalah film dengan durasi pendek antara 1-30 menit. Menurut standar festival internasional membagi beberapa jenis film pendek antara lain:

1. Film Pendek eksperimental. Film pendek yang digunakan sebagai bahan eksperimen atau uji coba, di Indonesia jenis film ini sering dikenal sebagai film Indie.

2. Film pendek komersial. Film pendek yang diproduksi untuk tujuan komersil atau memperoleh keuntungan, contohnya: iklan profil perusahaan

3. Film Pendek layanan masyarakat (Public Service Film). Film pendek yang bertujuan untuk layanan masyarakat, biasanya ditayangkan di media massa (televisi).

4. Film pendek Entertainment/hiburan. Film pendek yang bertujuan komersial untuk hiburan. Film ini banyak dijumpai di televisi dengan berbagai ragamnya.

Seperti yang dikemukakan Azhar Arsyad (2009), fungsi film memiliki tiga tujuan, yaitu untuk tujuan kognitif, tujuan psikomotor, dan tujuan afektif. Dalam hubungannya dengan tujuan kognitif, film dapat digunakan untuk:

1. Mengajarkan pengenalan kembali atau pembedaan stimulasi gerak yang relevan, seperti kecepatan objek yang bergerak, dan sebagainya.

2. Mengajarkan aturan dan prinsip. Film dapat juga menunjukkan deretan ungkapan verbal, seperti pada gambar diam dan media cetak. Misalnya untuk mengajarkan arti ikhlas, ketabahan, dan sebagainya.

3. Memperlihatkan contoh model penampilan, terutama pada situasi yang menunjukkan interaksi manusia.

Sementara untuk tujuan psikomotor, film digunakan untuk memperlihatkan contoh keterampilan gerak, dan tujuan afektif, bahwa film 
dapat mempengaruhi emosi dan sikap seseorang, yakni dengan menggunakan berbagai cara dan efek. Film merupakan alat yang cocok untuk memperagakan informasi afektif, melalui gambaran visual yang berkaitan.

Berdasarkan prinsip efektivitas media, film merupakan suatu media yang mempunyai beberapa keuntungan antara lain,

1. Film sangat baik menjelaskan suatu proses, bila perlu menggunakan "Slow Motion".

2. Setiap orang dapat belajar sesuatu dari film, baik yang pandai maupun yang kurang pandai.

3. Film dapat menampilkan kembali masa lalu dan menyajikan kembali kejadian yang telah lalu.

4. Film dapat mengembara dengan lincahnya dari satu negara ke negara yang lain, horizon menjadi amat lebar dan dunia luas.

5. Film dapat menyajikan teori atau pun praktik dari yang bersifat umum ke khusus atau sebaliknya.

6. Film dapat mendatangkan seorang ahli dan memperdengarkan suaranya.

7. Film dapat menggunakan teknik-teknik seperti warna, gerak lembut, dan sebagainya untuk menampilkan butir-butir tertentu.

8. Film dapat memikat perhatian masyarakat.

9. Film lebih realistis, dapat diulang-ulang, dihentikan, dan sebagainya sesuai kebutuhan, hal yang abstrak menjadi jelas.

10. Film dapat mengatasi keterbatasan daya indera kita.

11. Film dapat merangsang atau memotivasi kegiatan anak didik. (Sadiman, 2012).

\section{Metode Penelitian}

Penelitian ini menggunakan metode penelitian kualitatif dengan jenis penelitian studi kasus yang menghasilkan data deskriptif berupa kata-kata tertulis atau lisan dari orang-orang dan perilaku yang dapat diamati. Teknik pengumpulan data dilakukan secara trianggulasi (gabungan),

Adapun objek penelitian dalam penelitian ini adalah Biro Hubungan Masyarakat serta Direktorat Pendidikan dan Pelayanan Masyarakat (Dikyanmas) KPK yang melakukan strategi komunikasi dalam melakukan sosialisasi dan edukasi antikorupsi melalui penyelenggaraan Program AntiCorruption Film Festival (ACFFest) 2018 yang bertajuk "Integrity Start from You, Make Your Movie".

Informan dari penelitian ini adalah:

a. Direktorat Pendidikan dan Pelayanan Masyarakat (Dikyanmas) yang menjadi pelaksana program ACFFest 2018.

b. Biro Hubungan Masyarakat KPK yang mendukung program tersebut dengan strategi komunikasi, baik melalui publikasi maupun penanganan terhadap media.

Lokasi penelitian ini dilakukan pada Komisi Pemberantasan Korupsi (KPK) Khususnya pada Biro Humas KPK. 
Jenis penelitian dalam penelitian ini:

a. Data primer diambil langsung dari sumbernya dari pengamatan serta wawancara atas kegiatan-kegiatan mengenai strategi komunikasi.

b. Data sekunder berupa dokumen laporan kegiatan, laporan pemantauan media massa dan media sosial berita media massa, konten media sosial, website resmi KPK, akun media sosial terkait fokus peneliti.

Teknik pengumpulan data menggunakan:

a. Wawancara Mendalam, dibagi menjadi dua yaitu wawancara terstruktur dan wawancara tak terstruktur atau disebut juga wawancara mendalam.

b. Studi Dokumentasi, menggunakan dokumentasi berbentuk artikel, bukubuku teks, modul, jurnal serta website yang menunjang fokus penelitian.

Dalam penelitian ini instrumen penelitian yang utama adalah peneliti sendiri, namun setelah fokus penelitian menjadi jelas akan dikembangkan instrumen penelitian sederhana.

\section{Teknik Analisis Data}

Teknik analisis data yang digunakan dalam penelitian ini adalah analisis data kualitatif, mengikuti konsep yang diberikan Miles, Huberman dan Spradley. Analisis data kualitatif dilakukan secara interaktif dan berlangsung secara terus-menerus sampai jenuh. Aktivitas dalam analisis data, yaitu data reduction, data display, dan conclusion drawing/verification. Langkahlangkah analisis ditunjukkan pada gambar berikut.

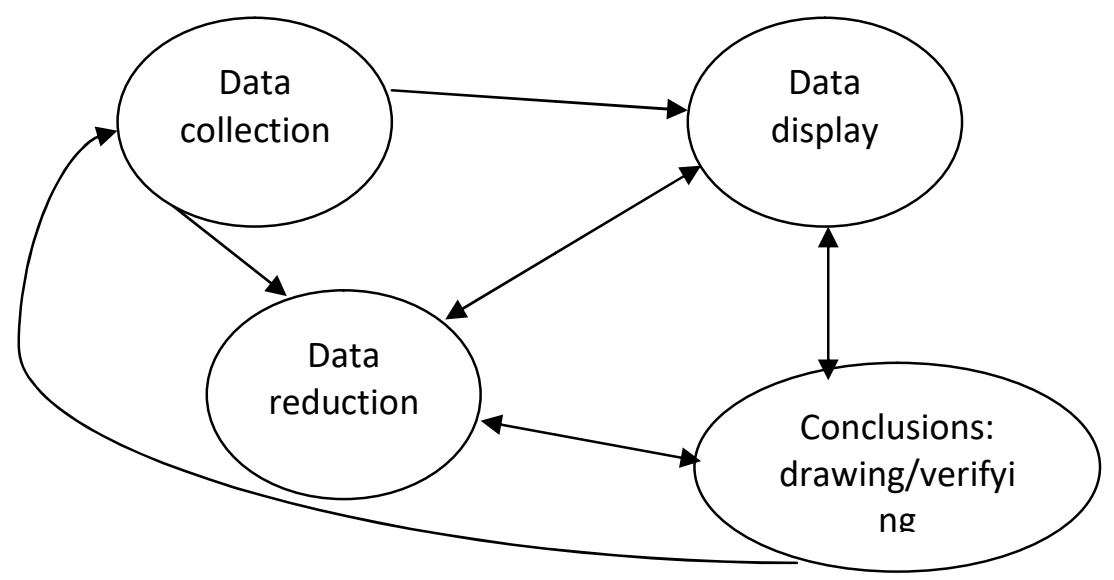

Gambar 2: Komponen dalam analisis data (interaktive model)

Pengujian kredibilitas data penelitian dilakukan dengan cara triangulasi. Penelitian ini menggunakan teknik triangulasi sumber, dengan cara:

a. Membandingkan data hasil pengamatan dengan data wawancara. 
b. Membandingkan hasil wawancara dengan isi suatu dokumen yang berkaitan.

\section{Pembahasan}

Tahap 1: Mencakup target sasaran (audience), pesan dan saluran.

Kegiatan ACFFest 2018 menargetkan para peserta dari kalangan pelajar SMA dan mahasiswa, berusia antara 15-20 tahun. Pada usia ini, diyakini sebagai generasi yang telah akrab dengan medium film. Program ACFFest 2018 menggunakan tema "Integrity Start from You, Make Your Movie". Bermakna remaja bisa mengambil peran dalam pencegahan korupsi dimulai dari upaya membangun dan menjaga integritas diri sendiri. Slogan "Dimulai dari diri sendiri, dimulai dari yang kecil dan dimulai sekarang juga" merupakan pesan sederhana praktis dalam memulai kampanye antikorupsi.

Proposal film yang diperlombakan sendiri bertema antikorupsi yang luas. Para peserta remaja diharapkan mampu menerjemahkan 9 nilai antikorupsi menjadi pesan sehari-hari, yakni jujur, peduli, mandiri, tanggung jawab, kerja keras, sederhana, adil, berani dan disiplin. KPK berharap, dengan menggunakan film sebagai saluran pesan antikorupsi, makin banyak masyarakat yang terpapar nilai-nilai baik ini. Sehingga akan memberikan pengetahuan, membentuk sikap dan menjadi perilaku dalam kehidupan sehari-hari.

\section{Tahap 2: Mencakup perencanaan untuk melakukan desain pesan, produksi media (draft), dan uji coba (pre-testing).}

\section{A. Promosi dan Publikasi}

Untuk mendapatkan tujuh proposal terbaik, KPK melakukan berbagai upaya sejak Juni hingga Desember 2018:

1. Peluncuran program ACFFest 2018. Secara resmi, program ACFFest 2018 diumumkan melalui konferensi pers pada 28 Juni 2018 di Gedung Merah Puth KPK. Dihadiri oleh Pimpinan KPK Saut Situmorang, Direktur Pendidikan dan Pelayanan Masyarakat KPK Sujanarko, serta dua sutradara juri ACFFest 2018 Jujur Prananto dan Kamila Andini.

2. Offair Promotion: Movie Day, Setelah konferensi pers, KPK 'bergerilya' ke beberapa kota untuk melakukan promosi. Strategi promosi dengan nama kegiatan "Movie Day" menjangkau lima kota yakni: Yogyakarta (26 Juli 2018), Banjarmasin (28 Juli 2018), Bali (3 Agustus 2018), Lampung (8-9 Agustus 2018) dan Bandung (8-9 Agustus 2018). Dihadiri lebih dari 1.000 orang yang berasal dari komunitas, pelajar dan mahasiswa. Terdiri dari beberapa kegiatan: 
pemutaran film, diskusi dengan Pimpinan KPK dan sineas profesional, mendiskusikan ide cerita film pendek yang akan dikompetisikan.

3. Media Visit, Setiap kali kegiatan Movie Day, KPK mengagendakan kunjungan media (media visit) ke satu televisi lokal dan dua radio lokal di tiap kota, guna mendorong promosi allow the line di media massa televisi dan radio agar informasi mengenai kegiatan ACFFest 2018 lebih menggema. Misalnya di TVRI lima daerah tersebut, dan radio Sonora Lampung, Sonora Banjarmasin, Sonora Bandung, dan lain-lain.

4. Online Promotion, Setidaknya ada dua media online dan empat media sosial yang digunakan, yaitu:

a. Website KPK www.kpk.go.id. Digunakan sebagai kanal resmi memberitakan kegiatan peluncuran, dan premier penayangan film.

b. Portal Anti-Corruption Clearing House (ACCH) di laman www.acch.kpk.go.id digunakan untuk medium registrasi proposal, informasi ketentuan pendaftaran, jadwal dan pengumuman.

c. KanalKPK, merupakan media tv dan radio streaming yang dikelola Biro Hubungan Masyarakat KPK. Promosi yang dilakukan yakni melalui talkshow pada program Bincang Kanal.

d. Media sosial KPK Facebook (Komisi Pemberantasan Korupsi), Twitter (@KPK_RI)dan Instagram (@official.kpk).

e. Instagram khusus program, yakni@acffest.kpk. secara intens mem-posting informasi, membangun keterlibatan (engagement) menghadirkan informasi antikorupsi dan kuis secara regular.

5. Media buying, memasang paket iklan berupa video promosi di media online Okezone.com pada 12-16 Juli 2018. Dimuat juga pada akun Instagram dan Channel Youtube Okezone. Ini merupakan satusatunya promosi berbayar yang dilakukan KPK.

\section{B. Praproduksi, Produksi dan Pascaproduksi}

Sebanyak 378 proposal diseleksi. Penilaian difokuskan pada kesesuaian tema dengan ide cerita. Proses kurasi proposal ini dilakukan sebanyak 2 kali oleh tim KPK pada tanggal 29 Agustus 2018. Setelah melewati sebanyak 2 kali proses kurasi, 27 proposal terpilih kemudian diajukan pada saat proses penjurian proses oleh dewan juri, yaitu bersama Jujur Prananto (Penulis Naskah), Kamila Andini (Sutradara), dan Edna Caroline Patissina (Kritikus Film). Proses penjurian proposal dilakukan pada 2 September 2018, yang memilih 7 proposal terbaik untuk mengikuti Movie Camp selama 3 hari.

Movie Camp diselenggarakan selama 3 hari di Jakarta. Sebanyak 14 peserta dari tujuh proposal mengikuti pembekalan materi tentang nilai-nilai antikorupsi oleh Pimpinan KPK. Peserta juga didampingi dewan juri untuk mempertajam proposal cerita, baik dari aspek alur cerita dan teknik 
penyutradaraan sehingga menghasilkan film yang berkualitas. Proses produksi dilaksanakan selama 3 bulan (September-November 2018), berbekal masukan-masukan para dewan juri. Selama produksi film, peserta didampingi oleh mentor lokal untuk memberikan masukan dan arahan agar film yang dihasilkan tetap bermutu dan menarik. Pada fase pascaproduksi, peserta melakukan editing secara mandiri, juga fasilitas editing secara online. Dewan juri memberikan masukan terhadap hasil editing mandiri yang telah dilakukan untuk menjaga kualitas film.

Setelah selesai produksi, KPK mengadakan sesi penjurian pada 22 November 2018 untuk menentukan Film Terbaik dan Film Pilihan Juri yang akan diumumkan bertepatan dengan penayangan Premier ACFFest pada 6 Desember 2018 di Jakarta. Film yang telah selesai diproduksi, akan dipublikasikan melalui KanalKPK yang dikelola Biro Humas KPK, dan akan ditayangkan secara langsung di empat kota pada Desember 2018, yakni Ambon (11-13 Desember), Pontianak (11-13 Desember), Jember (18-20 Desember) dan Padang (18-20 Desember).

\section{Peningkatan pengetahuan (knowledge), sikap (attitude) dan perilaku (practice) target sasaran yang diharapkan.}

Program ACFFest 2018 ditargetkan mampu menghasilkan tujuh film yang tak hanya menarik tetapi juga bermutu. Dari sini diharapkan, KPK memiliki amunisi yang akan digunakan untuk mengkampanyekan nilai-nilai antikorupsi pada masyarakat melalui film.

Sebelum menjawab mengenai peningkatan pengetahuan (knowledge), sikap (attitude) dan perilaku (practice), berikut uraian hasil yang telah dicapai, baik dari sisi output, maupun outcome program tersebut.

\section{Capaian output}

Dari serangkaian kegiatan, mulai dari promosi-publikasi hingga proses pra-produksi dan pascaproduksi. KPK menerima 378 proposal ide cerita dari 200 proposal yang ditargetkan, yang berasal dari berbagai daerah seperti Aceh, Lampung, Lahat, Jakarta, Bogor, Sukabumi, Yogyakarta, Tegal, Jember, Pontianak, Banjarmasin, Makassar, Bali Ambon dan Tidore.

Dari ratusan proposal yang masuk, kemudian dipilih tujuh proposal, yakni: 
Tabel 2. Demografi film peserta ACFFest 2018

\begin{tabular}{|c|c|c|c|}
\hline No & Judul Proposal & Asal Kota & Nilai \\
\hline 1 & Blessed & Jakarta & Kejujuran, kesederhanaan \\
\hline 2 & One Second & Jakarta & Kejujuran, keberanian \\
\hline 3 & $\begin{array}{l}\text { Sekeping Tanggung } \\
\text { Jawab }\end{array}$ & Bogor & $\begin{array}{l}\text { Tanggung jawab, kerja keras, } \\
\text { kejujuran }\end{array}$ \\
\hline 4 & Subur Itu Jujur & Ponorogo & Kerja keras, kejujuran, keadilan \\
\hline 5 & Kurang 2 Ons & Pontianak & Kejujuran, adil \\
\hline 6 & Baskara ke Wukir & Tegal & $\begin{array}{l}\text { Kejujuran, kerja keras, tanggung } \\
\text { jawab }\end{array}$ \\
\hline 7 & Jimpitan & Yogyakarta & $\begin{array}{l}\text { Tanggung jawab, sederhana, } \\
\text { gotong-royong }\end{array}$ \\
\hline
\end{tabular}

Sumber: Data olahan penulis

Dari target output (jumlah proposal), program ini dikatakan berhasil, karena telah melampaui jumlah proposal yang ditargetkan (189\%), dengan demografi peserta yang menyebar dari Indonesia timur, tengah dan barat yang cukup merata. Sementara bila dilihat dari sebaran topik dan nilai antikorupsi yang diangkat, juga cukup beragam, sehingga bisa menjangkau segmentasi penonton yang lebih luas.

\section{Capaian outcome}

Outcome atau dampak yang dihasilkan dari program tersebut, dapat dilihat dari aspek pemberitaan media massa dan media sosial sebagai medium promosi dan sosialisasi program.

\section{a. Media sosial}

Tabel 3. Statistik Media Sosial KPK

\begin{tabular}{cccc}
\hline & IG & FB & Twitter \\
\hline Jumlah Konten & 3 & 4 & 17 \\
Impression & 95.120 & 64.900 & 161.234 \\
Rerata Impression & 31.706 & 16.225 & 9.484 \\
Engagement & 2.451 & 1.145 & 1.315 \\
Rerata Engagement & 817 & 286,25 & 77,3
\end{tabular}

Sumber: Biro Humas KPK, 2019.

Total konten yang di-posting pada tiga media sosal KPK, yakni Facebook, Twitter dan Instagram, sebanyak 24 konten yang ditayangkan sepanjang 29 Juni hingga 7 Desember 2018. Dilihat dari data pada Tabel 3, Instagram dengan 396 ribu follower-nya, memiliki 
tingkat rata-rata penayangan (impression) dan keterlibatan (engagement) yang paling tinggi dibandingkan dengan Twitter dan Facebook, meski hanya mem-posting tiga konten saja, yakni rerata impression di atas 31 ribu dan rerata keterlibatan lebih dari 800 . Sementara Facebook dengan jumlah follower 1,3 juta, rata-rata impression pada empat konten ACFFest sebesar 16.225, sedangkan tingkat keterlibatan sebesar 286,25. Yang paling rendah adalah Twitter dengan rata-rata impression sebesar 9.484 dan rata-rata engagement sebesar 77,3.

Penyebab yang terjadi adalah: Pertama, karakteristik media sosial Twitter di KPK, lebih cocok untuk menyampaikan pesan pada bidang penindakan. Pengguna Twitter yang menjadi follower KPK didominasi usia di atas 35 tahun, sehingga konten bersifat lebih serius. Itu sebab, Twitter sering disebut sebagai medan perang "twitwar". Sedangkan Facebook dan Instagram lebih mudah menyerap isu pencegahan dengan konten kreatif berupa image dan video. Bisa dikatakan, audiens pada dua media sosial ini lebih 'damai'. Instagram sendiri didominasi oleh generasi muda berusia 18 tahun ke atas yang lebih menyukai konten image dan video ketimbang teks. Apalagi, fitur di Instagram juga atraktif, semisal story dan Instagram TV. Pengguna Facebook didominasi berusia 30 tahun ke atas. Hanya saja, fitur Facebook memungkinkan penggunanya menikmati konten yang beragam, mulai dari image, video, teks yang panjang, hingga kemampuan untuk siaran langsung (live).

Kedua, konten promosi dan sosialisasi program ACFFest 2018 lebih banyak berupa image dan video dengan menarget peserta dari generasi muda. Hal ini sangat cocok dengan karakteristik Facebook dan Instagram dengan fiturnya yang mampu mengakomodasi konten tersebut. Tidak hanya tinggi pada tingkat impression, konten yang kreatif juga mampu membangun keterlibatan (engagement), baik itu berupa like/love, save, klik dan menuliskan komentar, atau turut membagikan (share/repost) konten yang diunggah KPK. Sedangkan pada media sosial Twitter, konten image dan video dinikmati dengan terbatas. Tim pengelola media sosial KPK juga memahami bahwa perlakuan terhadap tiga media sosial tersebut juga sangat khas. Tidak semua konten cocok dengan media sosial tersebut. Sayangnya, tingginya tingkat impression dan engagement pada Instagram dan Facebook, tidak dimanfaatkan secara optimal oleh KPK dengan menghadirkan konten yang lebih kerap dan variatif. Instagram hanya mengunggah tiga konten, sementara Facebook hanya empat konten. Justru Twitter yang audiens lebih tua dan segmen isu yang tidak pas, 
mengunggah sebanyak 17 konten. KPK juga memiliki akun khusus program ACFFest 2018 pada Instagram @acffest.kpk. Pada akun ini, berisi konten lebih komprehensif, mulai dari masa pendaftaran, promosi, kegiatan Movie Camp, proses produksi, penjurian, testimoni peserta, hingga penayangan secara premier hasil film yang telah diproduksi. Tidak hanya konten yang bersifat informatif, akun ini juga mengundang keterlibatan dengan follower melalui kuis. Dengan 219 konten, akun ini memiliki rata-rata posting sebesar 0,37 per hari, 2,5 konten per pekan atau 8,5 konten per bulan. Dari sisi kuantitas, kurang optimal. Sedangkan dari sisi rata-rata keterlibatan (engagement) sebesar 118 (9,29\%), dengan 112 favorite $(8,81 \%)$ dan 6 komentar $(0,47 \%)$ tiap kontennya.

Dari Tabel 3, juga bisa dilihat bahwa konten promosi dan publikasi perkembangan program dari satu tahap ke tahap berikutnya, terlihat masih kurang. Kalau di rerata, hanya terdapat 8 konten per akun media sosial selama lima bulan program berjalan, atau 1,6 konten per bulan. Padahal, program ACFFest 2018 berlangsung sejak 28 Juni hingga 6 Desember 2018.

\section{b. Media publikasi online KPK.}

Website KPK. Publikasi pada website, terdiri dari: Dua berita kegiatan: 28 Juni (5.585 kali dilihat), 12 September (2.440 kali dilihat). Dua siaran pers yakni: 2 Juli (1.676 kali dilihat), 6 Desember (1.470 kali dilihat), KanalKPK. Publikasi pada radio dan tv KanalKPK berupa talkshow yang ditayangkan pada program Bincang Kanal (18 September 2018, sebanyak 136 kali dilihat). Pada publikasi media berbasis internet yang dikelola Biro Humas KPK, terlihat masih sedikit, terutama pada berita kegiatan di website KPK yang hanya menurunkan berita tentang peluncuran program ACFFest 2018 (28 Juni) dan persiapan produksi tujuh proposal film terpilih (12 September).

\section{c. Pemberitaan media massa.}

Pemberitaan tentang ACFFest 2018 ditemukan sebanyak lebih dari 201 berita di media massa berbasis internet. Sementara di radio, yang jelas tercatat, diberitakan di 10 radio lokal saat promosi dilakukan di lima kota. Sedangkan pemberitaan televisi, tercatat pada TVRI yang juga dilakukan saat promosi dilakukan di lima kota tersebut. Sayangnya, data pemberitaan tersebut tidak terekap dengan rapi dan sistematis sebagai acuan untuk melakukan intervensi publikasi. 


\section{d. Media Buying}

Video promosi program ACFFest di media online Okezone.com juga diunggah pada akun Instagram dan Channel Youtube Okezone. Sayangnya, tidak ada data jumlah yang mengakses video tersebut di situs tersebut. Pada channel Youtube terdapat 299 kali ditonton, sementara pada akun Instagram yang juga diunggah pada 12-16 Juli 2018 , terdapat lima konten dengan total love sebanyak 253 atau rerata 50,6 love per konten, serta 8 kometar, atau rerata 1,6 komentar per konten.

\section{e. Capaian}

Untuk capaian pada level pengetahuan (knowledge), sikap (attitude) dan perilaku (practice), KPK belum mengukur hal tersebut. Hal ini dapat diukur pada saat KPK melakukan penayangan (screening) pada target audiens yang sesuai dengan nilai-nilai film tersebut.

\section{Simpulan}

Dari sejumlah strategi komunikasi dan publikasi yang dilakukan KPK, program ACFFest 2018 dapat dikatakan berhasil. Pertama, hal ini dilihat dari jumlah proposal film yang masuk sebanyak 378 proposal dari 200 proposal yang ditargetkan. Kedua, KPK mengaku puas terhadap kualitas tujuh proposal terpilih yang kemudian diproduksi menjadi tujuh film pendek, dengan tema dan segmentasi yang beragam, juga dengan nilai antikorupsi yang kental.

Keberhasilan alasan pertama, dilihat dari strategi komunikasi offline yang tepat, dengan lebih banyak melakukan promosi langsung di kota-kota yang memiliki 'kantong' komunitas kreatif/film, remaja dan mahasiswa.

Keberhasilan alasan kedua, dapat dilihat ragam tema proposal terbaik dan kualitas film yang diproduksi. Ini disebabkan format ACFFest 2018 yang berbeda dari helatan sebelumnya, yakni dengan mengompetisikan ide cerita (proposal), sehingga KPK memiliki kesempatan dan ruang yang lebih besar untuk melakukan intervensi terhadap nilai-nilai antikorupsi yang akan dimasukkan dalam film pendek tersebut. Pada promosi allow the line perlu dioptimalkan, terutama dalam penggunaan media berbasis internet milik KPK, seperti media sosial (Facebook, Twitter dan Instagram) dan media online (website dan KanalKPK).

Koordinasi perlu ditingkatkan antara pengelola media-media tersebut dengan pelaksana program, agar konten ACFFest bisa ditayangkan lebih kerap dengan konten yang lebih variatif. KPK perlu mempertimbangkan untuk memantau dari medium mana para peserta mendapatkan informasi 
mengenai ACFFest, sehingga medium tersebut dapat dioptimalkan penggunaannya. Ke depan, penulis menilai perlu dilakukannya studi lanjutan untuk meneliti sejauhmana respons audiens (masyarakat) terhadap film-film tersebut, apakah nilai-nilai antikorupsi yang terkandung dalam film tersebut, sudah cukup efektif sehingga berdampak pada pemahaman/pengetahuan (knowledge), sikap (attitude) dan perilaku (practice) masyarakat.

\section{Referensi}

Azhar Arsyad, Media Pembelajaran. (2009). Jakarta: PT Grafindo Persada

Biagi, Shirley. (2010). Media Impact Pengantar Media Massa. Jakarta: Salemba Humanika,

Cangara, Hafied. (2013). Perencanaan dan Strategi Komunikasi. Jakarta: Rajawali Pers

Javandalasta, Panca. (2011). 5 Hari Mahir Bikin Film: Jangan Cuma Bisa Nonton, Ayo Bikin Film. Jakarta: Java Pustaka Group

McQuail, Denis. (1987). Teori Komunikasi Massa Suatu Pengantar. Jakarta: Erlangga,

Sadiman, Arief. (2011). Media Pendidikan. Jakarta: Rajawali Pers

Saiful Mujani Research \& Consulting, (2015), Memahami Pola Menonton Kaum Urban Muda Jakarta; Survei di Tiga Universitas di Jakarta

Sugiyono. (2007). Memahami Penelitian Kualitatif. Bandung: CV Alfabeta.

Undang-Undang Republik Indonesia nomor 33 Tahun 2009 Tentang Perfilman

Yin, Robert K., (2005). Studi Kasus Desain dan Metode. Jakarta: PT Rajawali Pers.

https://www.kpk.go.id/id/berita/berita-kpk/380-acffest-2018-jadikan-filmsebagai-inspirasi-lawan-korupsi , diakses 25 Februari 2019 https://www.kpk.go.id/id/berita/siaran-pers/384-gelar-acffest-kpk-ajakmasyarakat-buat-film-antikorupsi, diakses 25 Februari 2019 